\title{
A Remark on One Iterative Process for Finding the Roots of Equations
}

\author{
Dragomir M. Simeunović
}

Abstract. In this paper we consider the convergence of one iterative formula for finding the roots of equations.

It is well known that, if the equation

$$
x=f(x)
$$

has only one root $x=r$ in the interval $[a, b]$, and if the derivative $f^{\prime}(x)$ of the function $f(x)$ satisfies the condition

$$
\max \left|f^{\prime}(x)\right|=M<1, \quad \text { for } x \in[a, b],
$$

then the iterative method

$$
x_{k+1}=f\left(x_{k}\right), \quad k=0,1,2 \ldots,
$$

converges to the root $x=r$ of the equation (1), where the initial value $x_{0}$ can be any number from the interval $[a, b]$. The convergence of the process (3) is more rapid if $M$ has a small value.

In this paper we consider the values $f^{\prime}(a)$ and $f^{\prime}(b)$ and use it to determine $\max \left|f^{\prime}(x)\right|$.

Let $f^{\prime}(x)$ be a negative increasing function. Therefore, we have

$$
f^{\prime}(a) \leq f^{\prime}(x) \leq f^{\prime}(b)<0, \quad \text { for } \quad x \in[a, b] .
$$

From (4), we see that

$$
\max \left|f^{\prime}(x)\right|=\left|f^{\prime}(a)\right|
$$

and

$$
1-f^{\prime}(a)>0
$$

In (5), we have either

$$
\max \left|f^{\prime}(x)\right|=\left|f^{\prime}(a)\right|<1
$$

or

$$
\max \left|f^{\prime}(x)\right|=\left|f^{\prime}(a)\right| \geq 1 .
$$

2010 Mathematics Subject Classification. Primary: 65H05.

Key words and phrases. Iteration formulas, approximate solutions of equations. 
In both of these cases, we write the equation (1) in the form

$$
x=\frac{1}{1-f^{\prime}(a)}\left(f(x)-f^{\prime}(a) x\right),
$$

that is, in the form

$$
x=f_{1}(x),
$$

where

$$
f_{1}(x)=\frac{1}{1-f^{\prime}(a)}\left(f(x)-f^{\prime}(a) x\right) .
$$

From (11) we obtain

$$
f_{1}^{\prime}(x)=\frac{1}{1-f^{\prime}(a)}\left(f^{\prime}(x)-f^{\prime}(a)\right) .
$$

As $f^{\prime}(x)$ is an increasing function, considering (6), we conclude from (12) that the function $f_{1}^{\prime}(x)$ is also increasing.

From (12) we obtain

$$
f_{1}^{\prime}(a)=0, \quad f_{1}^{\prime}(b)=\frac{f^{\prime}(b)-f^{\prime}(a)}{1-f^{\prime}(a)}<\frac{-f^{\prime}(a)}{1-f^{\prime}(a)}<1 .
$$

From (13) follows that

$$
\max \left|f_{1}^{\prime}(x)\right|=\frac{f^{\prime}(b)-f^{\prime}(a)}{1-f^{\prime}(a)}<1 .
$$

Let $f^{\prime}(x)$ be a negative decreasing function. Therefore, we have

$$
0>f^{\prime}(a) \geq f^{\prime}(x) \geq f^{\prime}(b), \quad \text { for } \quad x \in[a, b] .
$$

From (15), we see that

$$
\max \left|f^{\prime}(x)\right|=\left|f^{\prime}(b)\right|
$$

and

$$
1-f^{\prime}(b)>0 .
$$

In (16), we have either

$$
\max \left|f^{\prime}(x)\right|=\left|f^{\prime}(b)\right|<1
$$

or

$$
\max \left|f^{\prime}(x)\right|=\left|f^{\prime}(b)\right| \geq 1 .
$$

In both of these cases, we write the equation (1) in the form

$$
x=\frac{1}{1-f^{\prime}(b)}\left(f(x)-f^{\prime}(b) x\right),
$$

that is, in the form

$$
x=f_{2}(x),
$$


where

$$
f_{2}(x)=\frac{1}{1-f^{\prime}(b)}\left(f(x)-f^{\prime}(b) x\right) .
$$

From (22) we obtain

$$
f_{2}^{\prime}(x)=\frac{1}{1-f^{\prime}(b)}\left(f^{\prime}(x)-f^{\prime}(b)\right) .
$$

As $f^{\prime}(x)$ is a decreasing function, considering (17), we conclude from (23) that the function $f_{2}^{\prime}(x)$ is also decreasing.

From (23) we obtain

$$
f_{2}^{\prime}(a)=\frac{f^{\prime}(a)-f^{\prime}(b)}{1-f^{\prime}(b)}<\frac{-f^{\prime}(b)}{1-f^{\prime}(b)}<1, \quad f_{2}^{\prime}(b)=0 .
$$

From (24) follows that

$$
\max \left|f_{2}^{\prime}(x)\right|=\frac{f^{\prime}(a)-f^{\prime}(b)}{1-f^{\prime}(b)}<1 .
$$

If the function $f^{\prime}(x)$ satisfies the condition (4), having (9) in mind, we can use the following iterative process for finding the root $x=r$ of the equation (1):

$$
x_{k+1}=\frac{1}{1-f^{\prime}(a)}\left(f\left(x_{k}\right)-f^{\prime}(a) x_{k}\right), \quad k=0,1,2 \ldots
$$

when $\max \left|f^{\prime}(x)\right|<1$ and when $\max \left|f^{\prime}(x)\right| \geq 1$.

If the function $f^{\prime}(x)$ satisfies the condition (15), having (20) in mind, we can use the following iterative process for finding the root $x=r$ of the equation (1):

$$
x_{k+1}=\frac{1}{1-f^{\prime}(b)}\left(f\left(x_{k}\right)-f^{\prime}(b) x_{k}\right), \quad k=0,1,2 \ldots
$$

when $\max \left|f^{\prime}(x)\right|<1$ and when $\max \left|f^{\prime}(x)\right| \geq 1$.

In [1, p. 145], the equation

$$
F(x)=0
$$

is considered, which has the root $x=r$ in the interval $[a, b]$ in the case

$$
0<m_{1} \leq F^{\prime}(x) \leq M_{1}, \quad \text { for } \quad x \in[a, b],^{1}
$$

where we can take

$$
m_{1}=F^{\prime}(a), M_{1}=F^{\prime}(b) .
$$

Now the condition (29) is reduced to

$$
F^{\prime}(a) \leq F^{\prime}(x) \leq F^{\prime}(b)
$$

\footnotetext{
${ }^{1}$ If $F^{\prime}(x)<0$ instead of equation $F(x)=0$ we consider the equation $-F(x)=0$.
} 
In this case the equation (28) can be written in the form

$$
x=x-\frac{1}{F^{\prime}(b)} F(x),
$$

that is, in the form

$$
x=\varphi(x)
$$

where

$$
\varphi(x)=x-\frac{1}{F^{\prime}(b)} F(x),
$$

wherefrom

$$
\varphi^{\prime}(x)=1-\frac{1}{F^{\prime}(b)} F^{\prime}(x) .
$$

Having (30) and (31) in mind, it follows from (34) that

$$
\max \left|\varphi^{\prime}(x)\right|=1-\frac{F^{\prime}(a)}{F^{\prime}(b)}=q<1 .
$$

Example 1. The equation

$$
F(x)=8 x^{3}-6 x-3=0
$$

has a root $x=r \in[1,2]=[a, b]$.

We can write the equation ( $a$ ) in the form

$$
x=\frac{3}{4 x}+\frac{3}{8 x^{2}},
$$

that is, in the form

$$
x=f(x),
$$

where

$$
f(x)=\frac{3}{4 x}+\frac{3}{8 x^{2}}
$$

From $\left(a_{2}\right)$ we obtain

$$
f^{\prime}(x)=-\frac{3}{4 x^{2}}-\frac{3}{4 x^{3}} .
$$

For $x \in[1,2]=[a, b]$ the function $f^{\prime}(x)$ is negative and increasing, and it holds that

$$
f^{\prime}(1)=f^{\prime}(a)=-\frac{3}{2}, f^{\prime}(2)=f^{\prime}(b)=-\frac{9}{32},
$$

which means that we can apply the formula (26) for finding the root $x=r \in$ $[1,2]$ of the equation $\left(a_{1}\right)$.

According to (5) and $\left(a_{4}\right)$, we have

$$
\max \left|f^{\prime}(x)\right|=\left|f^{\prime}(1)\right|=\left|f^{\prime}(a)\right|=\frac{3}{2}>1 .
$$


Having $\left(a_{4}\right)$ in mind, we obtain from (14)

$$
\max \left|f_{1}(x)\right|=\frac{39}{80} \text {. }
$$

From (a) we obtain

$$
F^{\prime}(x)=24 x^{2}-6,
$$

wherefrom

$$
F^{\prime}(1)=F^{\prime}(a)=18, F^{\prime}(2)=F^{\prime}(b)=90,
$$

which means that the condition (31) is satisfied.

For $x \in[1,2]=[a, b]$ the function $F^{\prime}(x)$ is increasing, and it holds that

$$
F^{\prime}(1)=F^{\prime}(a)=18, F^{\prime}(2)=F^{\prime}(b)=90 .
$$

The function $\varphi^{\prime}(x)$ in (34) is decreasing and having (a9) in mind, we obtain from (34)

$\left(a_{10}\right)$

$$
\max \left|\varphi^{\prime}(x)\right|=\frac{4}{5}
$$

Now the formula (32) is reduced to

$$
x=x-\frac{1}{90} F(x),
$$

from which follows the iterative process

$$
x_{k+1}=x_{k}-\frac{1}{90}\left(8 x_{k}^{3}-6 x_{k}-3\right), \quad k=0,1,2, \ldots .
$$

Having $\left(a_{2}\right)$ and $\left(a_{4}\right)$ in mind, the iterative process (26) is reduced to

$$
x_{k+1}=\frac{3}{5}\left(x_{k}+\frac{1}{2 x_{k}}+\frac{1}{4 x_{k}^{2}}\right), \quad k=0,1,2, \ldots,
$$

which converges more rapidly than the process $\left(a_{12}\right)$ for finding the root $x=$ $r \in[1,2]$ of the equation $(a)$, having $\left(a_{5}\right)$ and $\left(a_{10}\right)$ in mind. The initial value $x_{0}$ can be any number from the interval $[1,2]$.

\section{REFERENCES}

[1] Б.П. Демидович, И.А. Марон, Основы вычислительной математики (in Russian), Наука, Москва, 1970.

[2] Đuro Kurepa, Viša Algebra, 2. knjiga, Zavod za izdavanje udžbenika, Beograd, 1970.

Dragomir M. Simeunović Mike Alasa 8 11000 BELGRADE SERBia 